\title{
Perceived Similarities and Satisfaction among Friends of the Same and Different Ethnicity and Sex at Workplace
}

\author{
Intan H. M. Hashim ${ }^{1}$, Norzarina Mohd-Zaharim ${ }^{1}$, Siamak Khodarahimi ${ }^{2}$ \\ ${ }^{1}$ School of Social Sciences, Universiti Sains Malaysia, Penang, Malaysia \\ ${ }^{2}$ Eghlid Branch, Islamic Azad University, Eghlid, Iran \\ Email: hashimah@usm.my
}

Received April 18 ${ }^{\text {th }}, 2012$; revised May $20^{\text {th }}, 2012$; accepted June $22^{\text {nd }}, 2012$

\begin{abstract}
This study examined perceived similarities and satisfaction among friends who interacted at workplace. Respondents were 200 working adults in Malaysia. They were asked to identify the number of friends of the same and different ethnicity and sex at their workplace and then rate their satisfaction with these friendships. They were also asked to rate similarities with friends across nine domains (physical appearance, interest, life style, working style, thinking style, personality, values, general attitude, and intellectual ability). There were significant differences across domains and across categories of friends. More similarities were reported for working style and among friends of the same ethnicity. Lowest similarities were reported for physical appearance and among friends of different ethnicity. Differences in relationship satisfaction were rather minimal, whereas the highest satisfaction was with friends of the same ethnicity. Perception of similarities was associated with higher relationship satisfaction, with the strongest effect in the category of friends of the same ethnicity. Relationship satisfaction across all categories was negatively correlated with stress.
\end{abstract}

Keywords: Friendship; Similarities; Ethnicity; Relationship Satisfaction; Stress

\section{Introduction}

It has been well-established that similarities lead to attraction and formation of friendships. People are generally more attracted to those who are similar to them (Jussim \& Osgood, 1989; Rubin, 1973). People who share well-established relationships such as couples, friends, coworkers and members of informal organizations also tend to be more similar to each other than other randomly selected members of the same population (Goel, Manson, \& Watts, 2010; Kossinets \& Watts, 2009; Lasersfeld \& Merton, 1954).

Similarities among friends may come from three different sources; interpersonal influence, selective attraction and effects of shared environment (Jussim \& Osgood, 1989). In interpersonal influence, a person's attitudes, values or behavior can be directly affected by another person (Jussim \& Osgood, 1989). In this regard, a person may develop specific values that are similar (or perceived to be similar) to those of his or her friend's. In selective attraction, the similarity is assumed to exist prior to the establishment of the friendship and in fact is the factor that leads to the formation of that particular friendship. In intra-ethnic friendship, the same ethnicity becomes the basis of that relationship, illustrating the selective attraction process. Lastly, when two individuals share a similar environment, they may share the same experience that eventually leads to the same attitudes and values. In this effect, interpersonal influence is not what is leading to the same attitudes or values but rather the external effect of the environment that is more important.

According to attraction-similarity hypothesis, aspects of a relationship are what leading to perception of similarities (Morry, 2005). Based on this assumption, perceptions of similarity will be intensified during the course of relationships. This is particularly true for on-going relationships when a person is motivated to perceive more similarities with friends or significant others as part of their self or relationship-serving bias (Morry, 2005). In this study however, we are not concerned with the sources of similarities. Neither are we interested in whether attraction influences the perception of similarities. Instead, we are more interested to understand the dynamic interactions between similarity in sex and ethnic background.

In their research, Jussim and Osgood (1989) differentiated between objective and subjective interpersonal influence. They also suggested that when making an assessment on attitudes of a friend, there may be inaccuracies. However, subjective assessment of similarities remains a more powerful predictor of relationship satisfaction compared to more objective ratings. Similarly, Goel, Mason, and Watts (2010) found friends disagree more than they think and suggested a gap between real and perceived agreement. Both studies highlight that while subjective assessment is not always accurate, it is still important and powerful. The present study relies mostly on subjective perception of similarities.

Most studies on similarities also tend to focus on only one aspect of similarity at a time such as personality (Selfhout, Denissen, Branje \& Meeus, 2009) or attitudes (Goel et al., 2010). In one rare study that simultaneously looked at similarities among friends across activity preference and attitude, Werner \& Parmele (1979) found that activity preference similarity was substantially greater than attitudinal similarity. This study highlights the important of considering perception of similarities across different domains in the attempt to understand the more salient domains that can predict friendship's quality and satisfaction. Indeed as suggested by Duck (1973), even when examining a single domain similarity e.g. personal- 
ity, it is still important to be very precise about specific aspects of personality that are similar that can predict friendship choice at certain point of friendship development. The present study looked simultaneously at similarities across nine different domains including physical appearance, interest, life style, working style, thinking style, personality, values, general attitude and intellectual ability.

Researchers elsewhere have looked at similarities in friendship across different domains. For instance, Selfhout, Branje, ter Bogt and Meeus (2007) examined similarity in music preference and how it can contribute to friendship formation and discontinuation among adolescents. On the other hand, Eiser, Gammage, Brooks and Kirby (2009) have investigated similarity in smoking habits among best friends. These studies have selected various domains or aspects of similarity based on the interest and the focus of their study. Similarly, we selected these 9 domains based on the focus of this study which is similarity in friendship at work place. It is likely that in the context of friendship within work place, these domains play important but differential roles in determining friendship choice and maintenance. For instance similarity in working style may be more salient in determining the quality of friendships compared to similarity in physical appearance. In addition, we also compare the perceptions of similarities among people of the same and different ethnicity and sex. Are the perceptions of similarity relatively the same for friendships among people with the same sex and ethnicity and among people of different sex and ethnicity?

Workplace friendship has increasingly received more attention from researchers (Mao, 2006; Miller, Rutherford, \& Kolodinsky, 2008; Yen, Chen, \& Yen, 2009). Most work places provide ideal opportunities for people with different backgrounds to interact with each other and form friendships. This is especially true in the multiethnic setting of Malaysia. This study explored how people of different ethnicity and sex perceive similarities and rate satisfaction in their friendships.

\section{The Present Study}

There are 4 major objectives of the study. One is to examine respondents' perception of similarities with friends of similar and different ethnicity and sex across nine domains. The other is to examine respondents' relationship satisfaction with friends of similar and different ethnicity and sex. The third objective is to explore how respondents' perception of similarities with friends of similar and different ethnicity and sex influence relationship satisfaction. Lastly, this study also examines how respondent's relationship satisfaction with friends of similar and different ethnicity and sex influences perception of stress at work place.

\section{Method}

\section{Participants}

Participants were 200 working adults who were studying part-time in a distance learning program at a university in Malaysia. Sixty-six were males while 134 were females. They ranged in age from 22 to $53(M=32.3 ; S D=6.8)$. Majority are married (68.2\%). By ethnicity, Malays $(70.6 \%)$ formed a majority, followed by Indians $(15.4 \%)$, Chinese $(6 \%)$ and others $(8 \%)$. All of the respondents were working at the time of data collection with a large proportion working as teachers $(51.2 \%)$. Other occupations included government officers and techni- cal/clerical positions. Average years of working is $8.9(S D=$ 5.68 ) with income ranging from RM600 to RM6500 ( $M=$ RM2405, SD = RM866).

\section{Procedure}

Participants were recruited while on-campus as part of their course requirement. They were approached and asked to take part in the study. Upon agreement, they answered and returned a set of questionnaires immediately. They were paid some token money for participating.

\section{Measures}

General assessment of friendships at the workplace. In this section respondents responded to three items related to friendships at the workplace: 1) number of people considered friends at the workplace; 2) perception of similarity with these friends across 9 domains (physical appearance, interest, life style, working style, thinking style, personality, values, general attitude, and intellectual ability); and 3) satisfaction with these friendships. For similarities across different domains in general friends, respondents gave either a "yes" (indicating there are similarities between them and their friends across that particular domain) or a "no" (indicating no similarities) answer to each domain.

Assessment of intra-ethnic friendships at the workplace. Respondents responded to three items as described above, but in this section the items were particularly related to friendships with people of the same ethnicity. So, again, respondents indicated: 1) the number of people of the same ethnicity considered friends at the workplace; 2) their perception of similarity with these friends across 9 domains (physical appearance, interest, life style, working style, thinking style, personality, values, general attitude, and intellectual ability); and 3) their satisfaction with these friendships. As in general friends, respondents gave either a "yes" (indicating there were similarities between them and their friends across that particular domain) or a "no" answer (indicating no similarities) to each domain.

Assessment of inter-ethnic friendships at the workplace. Respondents responded to three items as described above, but in this section the items were particularly related to friendships with people of different ethnicity. So, again, respondents indicated: 1) the number of people of different ethnicity considered friends at the workplace; 2) their perception of similarity with these friends across 9 domains (physical appearance, interest, life style, working style, thinking style, personality, values, general attitude, and intellectual ability); and 3) their satisfaction with these friendships. Again "yes" indicates there were similarities and "no" indicates no similarities.

Assessment of intra-sex friendships at the workplace. Respondents responded to three items as described above, but in this section the items were particularly related to friendships with people of the same sex. So, again, respondents indicated: 1) the number of people of the same sex considered friends at the workplace; 2) their perception of similarity with these friends across 9 domains (physical appearance, interest, life style, working style, thinking style, personality, values, general attitude, and intellectual ability); and 3) their satisfaction with these friendships. Again "yes" indicates there were similarities and "no" indicates no similarities.

Assessment of inter-sex friendships at the workplace. Re- 
spondents responded to three items as described above, but in this section the items were particularly related to friendships with people of different sex. So, again, respondents indicated: 1) the number of people of different sex considered friends at the workplace; 2) their perception of similarity with these friends across 9 domains (physical appearance (PA), general interest (GA), life style (LS), working style (WS), thinking style (TS), personality $(\mathrm{P})$, values $(\mathrm{V})$, general attitude (GA), and intellecttual ability(IA)); and 3) their satisfaction with these friendships. Again "yes" indicates there were similarities and 'no' indicates no similarities.

Workplace Stress Scale (WSS; De Mello Alves et al., 2004). The WSS is a short version of Karasek's 49-item questionnaire. It is based on Karasek's conceptual model that involves aspects of stress in the workplace. The WSS includes three factors: demand (5 items, e.g., "Do you have to work very fast?"), control (6 items, e.g., "Do you have the possibility of learning new things through your work?"), and support (5 items, e.g., "There is a calm and pleasant atmosphere where I work"). Respondents respond to all items using a scale ranging from 1 (strongly agree) to 4 (strongly disagree). Reliability by Cronbach's alpha for all domains ranged from .63 to .86 (De Mello Alves et al., 2004). In the present study the responses were on a scale of 1 (strongly disagree) to 5 (strongly agree).

\section{Results}

Table 1 and 2 presented frequencies and mean of perceived similarities across domains and categories of friends. To test the significance of these differences, two sets of ANOVA were carried out; one across different types of friends and the other across different types of domains. From the first set of analysis, there was a significant effect of domains in similarities between all friends at work in general, $F(8.1592)=46.711, p<.005$, partial $\eta^{2}=.190$. There was a significant linear trend of the means for the factors, $F(1.199)=32.163, p<.005$, partial $\eta^{2}$ $=.139$. Participants reported highest similarities in working style with general category of friends, followed by general attitude and thinking style. Lowest similarities were reported for physical appearance.

There was also a significant effect of domains in similarities between friends of the same ethnicity at work, $F(8.1560)=$ $30.998, p<.005$, partial $\eta^{2}=.137$. There was a significant linear trend of the means for the factors, $F(1.195)=16.088, p$ $<.005$, partial $\eta^{2}=.076$. Similar to general category of friends, participants reported highest similarities in working style, followed by general attitude and thinking style with intra-ethnic friends. Lowest similarities were reported for physical appearance.

Again there was a significant effect of domains in similarities between friends of different ethnicity at work, $F(8.1424)=$ $24.813, p<.005$, partial $\eta^{2}=.122$. There was a significant linear trend of the means for the factors, $F(1.178)=21.580, p$ $<.005$, partial $\eta^{2}=.108$. Participants reported highest similarities in working style, followed by thinking style and general attitude. Lowest similarities were reported for physical appearance.

There was also a significant effect of domains in similarities between friends of the same sex at work, $F(8.1576)=32.315, p$ $<.005$, partial $\eta^{2}=.141$. There was a significant linear trend of the means for the factors, $F(1.197)=27.221, p<.005$, partial $\eta^{2}=.121$. Participants reported highest similarities in working style, followed by thinking style and general attitude. Lowest similarities were reported for physical appearance.

Finally, there was a significant effect of domains in similarities between friends of different sex at work, $F(8.1504)=$ $25.733, p<.005$, partial $\eta^{2}=.120$. There was a significant linear trend of the means for the factors, $F(1.188)=7.361, p<.05$, partial $\eta^{2}=.108$. Participants reported highest similarities in working style, followed by thinking style and general attitude. Lowest similarities were reported for physical appearance.

The second set of analysis tested the difference across different domains. There was no significant effect of similarities in physical appearance between different categories of friends, $F(4.692)=1.391, p=.235$, partial $\eta^{2}=.008$. There was no significant linear trend of the means for the factor, $F(1.173)$ $=.210, p=.648$, partial $\eta^{2}=.001$.

Table 1.

Percentages of respondents who perceived similarities with their friends across nine domains.

\begin{tabular}{lccccccccc}
\hline Friends & PA & GA & LS & WS & TS & P & V & GA & IA \\
\hline All & 5 & 40.3 & 32.2 & 65.7 & 55.3 & 25.4 & 27.4 & 27.4 & 61.2 \\
Same ethnicity & 3.5 & 37.3 & 31.3 & 54.2 & 50.1 & 24.9 & 30.3 & 30.3 & 49.3 \\
Different & 3 & 21.4 & 21.4 & 48.3. & 37.8 & 16.9 & 19.4 & 19.4 & 33.8 \\
ethnicity & & & & & & & & & \\
Same sex & 3.5 & 34.8 & 27.9 & 58.2 & 46.8 & 22.4 & 30.8 & 30.8 & 48.3 \\
Different sex & 4.5 & 26.4 & 24.4 & 52.7 & 40.8 & 17.9 & 23.9 & 23.9 & 39.3 \\
\hline
\end{tabular}

Table 2

Means of perceived similarities across domains and categories of friends.

\begin{tabular}{lccccccccc}
\hline Friends & PA & GA & LS & WS & TS & P & V & GA & IA \\
\hline All & & & & M (SD) & & & \\
Same ethnicity & $.046(.21)$ & $.393(.48)$ & $.316(.50)$ & $.668(.47)$ & $.549(.49)$ & $.258(.44)$ & $.247(.43)$ & $.609(.48)$ & $.478(48)$ \\
Different ethnicity & $.025(.15)$ & $.364(.48)$ & $.298(.45)$ & $.546(.49)$ & $.497(.50)$ & $.241(.43)$ & $.287(.45)$ & $.500(.50)$ & $.258(.43)$ \\
Same sex & $.034(.18)$ & $.248(.43)$ & $.241(.43)$ & $.529(.50)$ & $.439(.49)$ & $.183(.38)$ & $.224(.42)$ & $.379(.48)$ & $.281(.45)$ \\
Different sex & $.023(.15)$ & $.352(.49)$ & $.258(.44)$ & $.598(.49)$ & $.485(.50)$ & $.218(.41)$ & $.304(.46)$ & $.477(.50)$ & $.287(.45)$ \\
& $.057(.29)$ & $.277(.46)$ & $.258(.43)$ & $.552(.49)$ & $.416(.49)$ & $.189(.39)$ & $.247(.43)$ & $.402(.49)$ & $.189(.39)$ \\
\hline
\end{tabular}


There was a significant effect of similarities in general interest between different categories of friends, $F(4.688)=5.541, p$ $<.005$, partial $\eta^{2}=.031$. There was a significant linear trend of the means for the factor, $F(1.172)=6.648, p<.05$, partial $\eta^{2}$ $=.037$. Participants reported lowest similarity in general interest with friends of different ethnicity, followed by friends of different sex. Similarities in general interest were highest with friends of the same ethnicity.

There was no significant effect of similarities in life style between different categories of friends, $F(4.692)=1.317, p$ $=.262$, partial $\eta^{2}=.008$. There was no significant linear trend of the means for the factor, $F(1.173)=2.801, p=.096$, partial $\eta^{2}=.016$.

There was a significant effect of similarities in working style between different categories of friends, $F(4.684)=4.209, p$ $<.05$, partial $\eta^{2}=.024$. There was a significant linear trend of the means for the factor, $F(1.171)=4.519, p<.05$, partial $\eta^{2}$ $=.026$. Participants reported lowest similarity in working style with friends of different ethnicity, followed by friends of different sex. Similarities in working style were highest with friends of the same ethnicity.

There was a significant effect of similarities in thinking style between different categories of friends, $F(4.688)=3.565, p$ $<.05$, partial $\eta^{2}=.049$. There was a significant linear trend of the means for the factor, $F(1.172)=8.924, p<.005$, partial $\eta^{2}$ $=.049$. Participants reported lowest similarity in thinking style with friends of different ethnicity, followed by friends of different sex. Similarities in thinking style were highest with friends of the same ethnicity.

There was no significant effect of similarities in personality between different categories of friends, $F(4.692)=1.931, p$ $=.104$, partial $\eta^{2}=.011$. There was no significant linear trend of the means for the factor, $F(1.173)=3.584, p=.060$, partial $\eta^{2}=.020$.

There was no significant effect of similarities in values between different categories of friends, $F(4.692)=1.831, p=.111$, partial $\eta^{2}=.010$. There was no significant linear trend of the means for the factor, $F(1.173)=.036, p=.849$, partial $\eta^{2}$ $=.000$.

There was a significant effect of similarities in general attitude between different categories of friends, $F(4.692)=10.215$, $p<.005$, partial $\eta^{2}=.056$. There was a significant linear trend of the means for the factor, $F(1.173)=19.613, p<.005$, partial $\eta^{2}=.102$. Participants reported lowest similarity in general attitude with friends of different ethnicity, followed by friends of different sex. Similarities in general attitude were highest with friends of the same ethnicity.

There was a significant effect of similarities in intellectual ability between different categories of friends, $F(4.692)=5.587$, $p<.005$, partial $\eta^{2}=.0531$. There was a significant linear trend of the means for the factor, $F(1.173)=11.646, p<.005$, partial $\eta^{2}=.063$. Participants reported lowest similarity in intellectual ability with friends of different sex, followed by friends of the same ethnicity. Similarities in intellectual ability were highest with friends of the same gender.

ANOVA was also carried to test the difference level of satisfaction among different categories of friendship. There was a significant effect of relationship satisfaction between different categories of friends, $F(4.684)=9.375, p<.005$, partial $\eta^{2}$ $=.052$. There was a significant linear trend of the means for the factor, $F(1.171)=20.774, p<.005$, partial $\eta^{2}=.108$. From Table 3, participants reported lowest satisfaction with friends of different sex, followed by friends of different ethnicity. Satisfaction was highest with friends of the same ethnicity.

Finally correlation analyses were carried between perception of similarities and relationship satisfaction and stress across different categories of friend. There were significant correlations between perception of similarities with friends of different categories and relationship satisfaction (see Table 4). However, the correlation between perception of similarities with friends of different sex and relationship satisfaction with those friends was not significant, $p>.05$. Finally, there were significant correlations between relationship satisfaction with friends all different categories and stress at work (see Table 5).

\section{Discussion}

Participants in the study perceived and reported more similarities with friends in working style and intellectual ability more than in other domains. They perceived lowest similarities in physical appearance. This suggests that even though people are generally attracted to those who are similar to them, perhaps at least in workplace environment, similarities in some domains the least important in friendship formation and maintenance at the workplace but similarities in working style and intellectual ability are more important.

Table 3.

Means of relationship satisfaction with friends of the same and different ethnicity and sex.

\begin{tabular}{lc}
\hline Category of friends & $M(S D)$ \\
\hline All & $4.15(.53)$ \\
Same ethnicity & $4.16(.54)$ \\
Different ethnicity & $4.02(.59)$ \\
Same sex & $4.04(.58)$ \\
Different sex & $3.98(.62)$ \\
\hline
\end{tabular}

\section{Table 4.}

Correlations between perceptions of similarities with friends of the same and different ethnicity and sex and relationship satisfaction with the friendships.

\begin{tabular}{lc}
\hline Category of friends & $n=200$ \\
\hline All & $.15^{*}$ \\
Same ethnicity & $.23^{* *}$ \\
Different ethnicity & $.15^{*}$ \\
Same sex & $.14^{*}$ \\
Different sex & .04 \\
\hline
\end{tabular}

Note: ${ }^{*}$ Correlation is significant at the .05 level (2-tailed). ${ }^{* *}$ Correlation is significant at the .01 level (2-tailed).

Table 5.

Correlations between relationship satisfaction with friends of the same and different ethnicity and sex and stress.

\begin{tabular}{ll}
\hline Category of friends & $n=200$ \\
\hline All & $-.27^{* *}$ \\
Same ethnicity & $-.26^{* *}$ \\
Different ethnicity & $-.30^{* *}$ \\
Same sex & $-.33^{* *}$ \\
Different sex & $-.21^{* *}$ \\
\hline
\end{tabular}

Note: ${ }^{*}$ Correlation is significant at the .05 level (2-tailed). ${ }^{* *}$ Correlation is significant at the .01 level (2-tailed). 
Participants in the study also perceived more similarities with friends of the same ethnicity compared to friends with different ethnicity. Similarly, they perceived more similarities with friends of the same sex compared to friends of different sex. They also perceived more similarities with friends of the same ethnicity than friends of the same sex. Differences in relationship satisfaction were rather minimal, with highest satisfaction among friends of the same ethnicity. Perception of similarities was associated with higher relationship satisfaction, with the strongest effect among friends of the same ethnicity. These findings indicate the centrality of ethnicity in friendships in multiethnic Malaysia. As suggested by the findings on shared similarities and relationship satisfaction, Malaysians prefer friends of the same ethnicity.

Relationship satisfaction for all categories of friends had significant negative correlations with stress. Thus, Malaysians facing work stress might be buffered by the quality of friendships at the workplace, regardless of the ethnicity and sex of their friends.

These findings have several implications. Friendships at work place should be encouraged as it can have protective element against stress. One way to encourage these friendships is by allowing people to work together that will provide opportunity for them to discover their potential similarity, especially in terms of working style and intellectual capacity. Although this method can backfire in cases when people found themselves to be different, but more opportunity to work together may increase attraction and perception of similarity. Although people still prefer to develop friendships with those of similar ethnicity, this study also highlights the important of similar sex friendships. Similar sex friendships may cut across ethnicity and allow people of different ethnicity but similar sex to develop and maintain meaningful and satisfying relationships that in turn can improve inter-ethnic relationships in a multi-cultural society such as Malaysia.

This study is somewhat limited in a number of ways. One is the small sample with small ethnic variations that can limit the application of the findings. Future studies may include a larger population focusing on work place that represents all ethnic groups in Malaysia better. In this study, assessment of similarities for each domain relied on a single item measure. Future studies may use more than one item to measure similarities across different domains.

As a conclusion, this study highlights the important of understanding the complicated process underlying perceptions of similarities among friends and the need for more refined theories on friendships, as occurred within work place situations.

\section{Acknowledgements}

This research was funded by Research University Grants of Universiti Sains Malaysia, Malaysia.

\section{REFERENCES}

Aboud, F. E. (2003). The formation of in-group favoritism and out-group prejudice in young children: Are there distinct attitudes? Development Psychology, 39, 48-60. doi:10.1037/0012-1649.39.1.48
Bellmore, A. D., Nishina, A., Witkow, M. R., Graham, S., \& Juvonen, J. (2007). The influence of classroom ethnic composition on sameAnd other-Ethnicity peer nominations in middle school. Social Development, 16, 720-740. doi:10.1111/j.1467-9507.2007.00404.x

Aminudin, M. Y., Arifin, Z., Khaidzir, I., Fatimah W. H., Suzana, M. H., Siti, W. S., \& Yuzana, M. Y. (2006). Pemetaan sikap etnik mengikut zon-zon di Malaysia. Prosiding Seminar Psikologi Pembangunan Komuniti ISM-UKM. Kuala Lumpur: Institut Sosial Malaysia.

Breckler, S. J., Olson, J., \& Wiggins, E. (2006). Social psychology alive. Boston: Thomson Wadsworth.

Dovidio, J. F., \& Gaertner, S. L. (2000). Aversive racism and selection decisions; 1989-1999. Psychological Science, 11, 315-319. doi: $10.1111 / 1467-9280.00262$

Duck, S. W. (1973). Personality similarity and friendship choice: Similarity of what, when? Journal of Personality, 41, 543-558. doi:10.1111/j.1467-6494.1973.tb00110.x

Eiser, J. R., Morgan, M., Gammage, P., Brooks, N., \& Kirby, R. (2009). Adolescent health behaviour and similarity-attraction: Friends share smoking habits (really), but much else besides. The British Journal of Social Psychology, 30, 339-348.

doi:10.1111/j.2044-8309.1991.tb00950.x

Emerson, M. O., Kimbro, R. T., \& Yancey, G. (2002). Contact theory extended: The effects of prior racial contact. Social Science Quarterly, 83, 745-761. doi:10.1111/1540-6237.00112

Feddes, A. R., Noack, P., \& Rutland, A. (2009). Direct and extended friendship effects on minority and majority children's interethnic attitudes: A longitudinal study. Child Development, 80, 377-390. doi:10.1111/j.1467-8624.2009.01266.x

Goel, S., Mason, W., \& Watts, D. J. (2010). Real and perceived attitude agreement in social networks. Journal of Personality and Social Psychology, 99, 611-621. doi:10.1037/a0020697

Hashim, I. H. M. (2006). Who provides what: A study on interpersonal relationships of university students. Prosiding Seminar Psikologi Pembangunan Komuniti ISM-UKM. Kuala Lumpur: Institut Sosial Malaysia.

Hashim, I. H. M. (2007). The development of friendships and its relationship with loneliness. 19th Asia-Pacific Social Work Conference, Penang, 4-6 September 2007.

Hashim, I. H. M. (2007). Stress, coping and social supports in the adolescent years. Kajian Malaysia, 25, 97-115.

Hashim, I. H. M. (2005). The development of social network at workplace for new teachers. Kajian Malaysia, 23, 35-61.

Jussim. L., \& Osgood, D. W. (1989). Influence of similarity among friends: An integrative model applied to incarcerated adolescents. Social Psychology Quarterly, 52, 98-112. doi:10.2307/2786910

Pettygrew, T. F. (1998). Intergroup contact theory. Journal of Personality and Social Psychology, 90, 751-783. doi:10.1037/0022-3514.90.5.751

Roberts, R., Phinney, J., Masse, L., Chen, Y., Roberts, C., \& Romero, A. (1999). The structure of ethnic identity in young adolescents from diverse ethnocultural groups. Journal of Early Adolescence, 19, 301-302. doi:10.1177/0272431699019003001

Rubin, Z. (1973). Liking and loving. New York: Holt, Rinehart and Winston.

Selfhout, M., Denissen, J., Branje, S., \& Meeus, W. (2009). In the eye of beholder: Perceived, actual and peer-rate similarity in personality, communication, and friendship intensity during the acquaintanceship process. Journal of Personality and Social Psychology, 96, 11521165. doi: $10.1037 / \mathrm{a} 0014468$

Werner, C., \& Parmele, P. (1979). Similarity of activity preference among friends: Those who play together, stay together. Social Psychology Quarterly, 42, 62-66. doi:10.2307/3033874

Verkutyen, M. (2002). Ethnic attitudes among minority and majority children: The role of ethnic identification, peer group victimization, and parents. Social Development, 11, 558-570.

doi:10.1111/1467-9507.00215 